\title{
Influence of Allium Sativum (Garlic), Zingiber officinale (Ginger) and Syzygium aromaticum (Clove) Extract against Larvae of Aedes mosquitoes (Culicidae: Diptera)
}

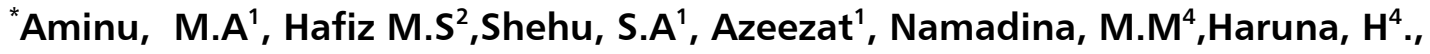 \\ Mukhtar M. $\mathbf{M}^{2}$, , Tasi'u, $S^{5}$, Yunusa A. $Y^{6}$, Biliyaminu $A^{7}$, Umar A.B ${ }^{8}$., Maitama, F. ${ }^{1}$ \\ ${ }^{1}$ Department of Biological Sciences, \\ Bayero University \\ Kano-Nigeria \\ ${ }^{4}$ Department of Biological Sciences, \\ Federal University of Kashere, \\ Gombe State-Nigeria \\ ${ }^{3}$ Department of Biochemistry, \\ Bayero University \\ Kano-Nigeria \\ ${ }^{4}$ Department of Plant Biology, \\ Bayero University, \\ Kano-Nigeria \\ ${ }^{5}$ Department of Biological Sciences, \\ Federal University Dutsin-MA, \\ Katsina State-Nigeria \\ ${ }^{6}$ Department of Biological Sciences, \\ Federal University Wukari, \\ Taraba state-Nigeria \\ ${ }^{7}$ Department of Biology, \\ Jigawa State College of Education \\ Gumel, Jigawa State - Nigeria \\ ${ }^{8}$ Department of Biological Sciences, \\ Yusuf Maitama Sule University \\ Kano-Nigeria
}

\begin{abstract}
Mosquito control has become more difficult due to the unsystematic use of synthetic chemical insecticides which have inauspicious effect on the environment. Botanical phyto-chemicals with mosquitocidal potential are now recognized as potent alternative insecticides to replace synthetic insecticides in mosquito control programs due to their excellent larvacidal activities. The present
\end{abstract}


study assessed the influence of A. sativum (garlic), Z. officinale (ginger) and S. aromatic (clove) extracts against Aedes mosquitoes. Larvacidal activities of three indigenous plant extracts were studied in the range 5.0 to $30.0 \mathrm{mg} /$ in the laboratory bioassay against fourth instar larvae of Aedes $s p$. The mortality were subjected to probit analysis to determine the lethal concentration $\left(L C_{50}\right)$ to kill 50 percent of treated larvae of Aedes sp. Data obtained were analyzed by Comparing experimental groups and control groups with significance level established at $p<0.05$. All plants tasted showed effects after $24 \mathrm{hrs}$ of exposure at different concentration $(\mathrm{mg} / \mathrm{l})$. However the highest mortality was found in A. Sativum (garlic) and Z. officinale (ginger) against larvae of Aedes mosquitoes with $L_{50}$ $=42.50 \%(2.685)$ and $L C_{50}=30.01 \%(4.461) \mathrm{mg} / \mathrm{l}$, while $S$. aromatic(clove) was found to have lowest mortality at $L C_{50}=24.50 \%$ (5.52) respectively. It is therefore recommended that A. sativum(Gallic), S. aromatic (Clove) has showed larvacidal effects against Aedes mosquitoes and could be served as alternative form of botanical control against mosquitoes .

Keywords: A. sativum (garlic), Z. officinale (ginger) and S. aromatic (clove), Extracts, Aedes mosquitoes

\section{INTRODUCTION}

Mosquito control methods mainly rely on the chemical insecticides, but has led to environmental pollution (Barnard, 1999). Mosquito control has become more difficult due to the unsystematic use of synthetic chemical insecticides which have inauspicious effect on the environment (Das et al., 1997), The larval stages of mosquitoes can easily be eradicated for control operations because they are less movable in larval forms than the adults (Benelli, 2015). To control or eliminate mosquito population highly efficacious pesticides have been employed (Downe, 1975). These pesticides are threatened due to the developing resistance of mosquitoes against them (Edriss et al., 2012).Therefore, alternative biological mosquitocides are urgently needed. Plants are considered as a rich source of bioactive chemicals and they may be an alternative source of mosquito control agents (Arsenaul et al., 2008). Phytochemical with mosquitocidal potential are now recognized as potent alternative insecticides to replace synthetic insecticides in mosquito control programs due to their excellent larvicidal and Adulticidal properties (De Souza et al., 2011).

Therefore, alternative biological mosquitocides are urgently needed. Plants are considered as a rich source of bioactive chemicals and they may be an alternative source of mosquito control agents (Arsenaul et al., 2008). The chemicals derived from plants have been projected as weapons in future mosquito control program as they are shown function as general toxicant, growth and reproductive inhibitors, repellents and oviposition-deterrent (Ferdouse, 2005).

Some of the active compounds of interest are ocimenone from Tagetes minuta (Maradufu et al., 1998), rotenone from Derris elliptica (Ameen et al., 1983), azadirachtin from Azadirachta indica (Schmutterer, 1981), capillin from Artemisia nilagiric (Banerji et al., 1990), quassin from Quassia amara (Evans, 1991), neolignans from Piper decurrens (Chauret et al., 1996).

There have been many attempts to assay the activity of plant extracts against vectors of human disease, in particular through the utilization of plants for which such knowledge exists (Hafeez et al., 2011). Plant extracts contain botanical insecticides or phytochemicals that could be used to limit reproduction and survival of various pest species including mosquitoes (Haque et al., 2009). Mosquitoes are of much concern to public health and wellbeings of the global human population (James, 2016). Since these mosquitoes transmit a 
number of dreadful diseases like filarial, malaria, elephantiasis and dengue, control measures using non-conventional insecticides like botanicals and phytochemical derivatives are gaining much attention in recent days due to a number of favorable reasons (Gericke, 2002). the impacts of phytochemicals on mosquito control strategies reveals some encouraging information on insecticides of plant origin have been tested to be specific in action against target insects and are non-toxic on the ecosystem and man as compared to the chemical compounds (Jeyabalan et al., 2003).

One can speculate that people controlled and killed mosquitoes and other domestic insect pests by physically removing them or by using plant parts and plant derivative before the advent of synthetic chemicals. Larger number of human Population in this world of about $80 \%$ depends largely in plants for its health care control of infectious and non-infectious diseases (Werka et al., 2007) Therefore, plants extracts are gaining acceptance in providing alternative majors in vector control of diseases and arboviruses due to their non-toxicity, specificity, and are safe to the environment and ecosystem and have lesser effects to the flora and fauna (Ormancey et al 2008). Therefore in the present study, I have screened three endemic plants A. Sativum (garlic), Z. officinale (ginger) and S. aromatic (clove) extracts leaves extract on the larvicidal activities against Aedes mosquitoes. The possible result of the present study would be useful in promoting research aiming at the development of new agent for mosquito control based on bioactive compounds from indigenous endemic medicinal plant source.

\section{MATERIALS AND METHODS}

\section{Collection and Rearing of Mosquitoes}

Reared mosquito larvae of Aedes mosquito were obtained from tidal pole or stagnant water at the Department of Biological sciences, Bayero University Kano, Nigeria.

Larvae of Aedes sp were maintained under standard and constant laboratory rearing conditions. Around 100 larvae were reared under relaxed conditions of low larval density (1larva/ $5 \mathrm{ml}$ ) in each standard rearing tray with $1 \mathrm{~L}$ of de-chlorinated water with $50 \mathrm{ml}$ of bovine liver or slurry or yeast diet given daily (Lutomiah et al., 2007).

\section{Collection and Identification of Plant Materials}

Plants materials such as A. Sativum (garlic), Z. officinale (ginger) and S. aromatic (clove) leaves were obtained from Goron-maje village, Dambatta LGA, Kano State. The plants were authenticated by an expert in plant taxonomy at the Department of Plant Biology, Bayero University Kano.

\section{Preparation of Plant Extracts}

A. sativum, Z. officinale and S. aromatic were washed in tap water, cut into small pieces and air dried. After the plants were completely dry, they were ground into powder and then macerated in an aqueous solvent at room temperature for 3 days and then filtered. The combined filter was concentrated to dryness by rotary evaporation and kept in a freezer. The prepared test concentration of each plant extract was volumetrically diluted with water.

\section{BIOASSAY}

\section{Larvacidal Assay}

A stock solution of plant extract was prepared by dissolving $100 \mathrm{mg}$ of extract in $1 \mathrm{ml}$ of distilled water. initial concentration of plant extract $(100 \mathrm{mg} / \mathrm{ml})$ were diluted using double fold serial dilution by transferring $1 \mathrm{ml}$ of sterile plant extract (stock solution) to obtain 50 $\mathrm{mg} / \mathrm{ml}$ concentration (Jidong et al., 2009). The above process will be repeated several times to obtained other dilution $5.0 \mathrm{mg} / \mathrm{ml}, 12.0 \mathrm{mg} / \mathrm{ml}, 20.0 \mathrm{mg} / \mathrm{ml}, 25.0 \mathrm{mg} / \mathrm{ml}$ and $30.0 \mathrm{mg} / \mathrm{ml}$. 
The mortality rate was subjected to probit analysis to determine the lethal concentration (LC50 and LC90) to kill 50 to $90 \%$ of the larva and pupae respectively. Determination of LC50 and LC90 values at 90\% confident limit was estimated or calculated Using: LC50 = $\mathrm{ABY}^{2}$, (Edillo et al., 2004)

Where, $A=$ highest toxicant concentration in which none of the test organism died, and $B=$ lowest concentration. Determination of immature stages would be determined according to the techniques of (Edillo et al., 2001).

\section{Data Analysis}

Data were base on Excel (Microsoft Co.). Comparison between treatment and control groups, were performed using analysis of variance (ANOVA). Probit analysis program was used to determine $\mathrm{LC}_{50}$ between concentration and percentage mortality at various concentrations of plant extracts. Abbott's formula was used to analyze the data of mortality obtained through bioassay test and statistical tools (Abbott, 1999).

\section{RESULTS}

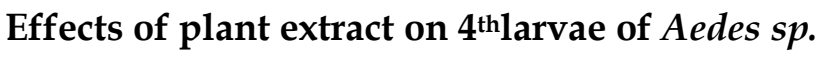

The activity of plant extract is often attributed to the complex mixture of active compounds. In the preliminary screening, potential larvacidal activity of different plant extracts $A$. sativum, Z. officinale and S. aromatic were noted (table 1\& fig.1 ) with seven (7) replicates against Aedes sp and percentage mortality was observed in A. sativum 134 (19.14) Z. offinale 147 (21.00) and S. aromatic 196 (32.42) respectively (Table 1). Data obtained were analyzed by comparing experimental groups and control groups with significance level established at $\mathrm{p}<0.05$.

Table 1: Preliminary screenings of different Plant extracts against $4^{\text {th }}$ Instars larvae of Aedes $s p$

\begin{tabular}{|c|c|c|c|}
\hline Plant material/Extracts & $\begin{array}{c}\text { Larvae } \\
4^{\text {th }} \text { instars }\end{array}$ & $\begin{array}{c}\text { Total } \\
\text { Mortality/Replication }\end{array}$ & Means \pm SD \\
\hline A. sativum & Aedes sp & $134(5)$ & $19.14 \pm 2.685$ \\
\hline Z. officinale & Aedes sp & 147(5) & $21.00 \pm 4.461$ \\
\hline S. aromatic & Aedes sp & 196(5) & $32.42 \pm 5.52$ \\
\hline
\end{tabular}

$\mathrm{SD}=$ Standard deviation,

\section{$\mathrm{LC}_{50}$ (Lethal Concentration at $50 \%$ ) on Aedes larvae}

All plants extracts show toxic effects on Aedes $s p$ after $24 \mathrm{~h}$ of exposed at different concentration (mg/l). However the highest mortality was found in A. sativum and Z. officinale against larvae of Aedes mosquitoes with $\mathrm{LC}_{50}=42.50 \%$ (2.685) and $\mathrm{LC}_{50}=30.01 \%(4.461)$ $\mathrm{mg} / 1$ respectively (Table.2) while $S$. aromantic was found to have lowest mortality at $\mathrm{LC}_{50}=$ $24.50 \%$ (5.52). 
Influence of Allium Sativum (Garlic), Zingiber officinale (Ginger) and Syzygium aromaticum (Clove) Extract against Larvae of Aedes mosquitoes (Culicidae: Diptera)

Table 2: $\mathrm{LC}_{50}$ Statistical analysis of different plant with aqueous solvent (Extracts) against larvae of Aedes sp (mortality)

\begin{tabular}{ccc}
\hline Plants Species & Solvent & $\begin{array}{c}\mathrm{LC}_{50} \pm \mathrm{SE} \\
(\mathrm{mg} / \mathrm{L})\end{array}$ \\
\hline A. sativum (Gallic) & Aqueous & $30.01 \pm 7.10$ \\
Z. officinale (Ginger) & Aqueous & $24.50 \pm 11.80$ \\
S. aromatic (Clove) & Aqueous & $42.50 \pm 14.61$ \\
\hline
\end{tabular}

$\mathrm{LC}_{50}=$ Lethal concentration that kills $50 \%$ of exposed larvae; Control= Nil mortality; SE= Standard error; Comparing experimental and control group, with a significant level established at $\mathrm{P}<0.05$.

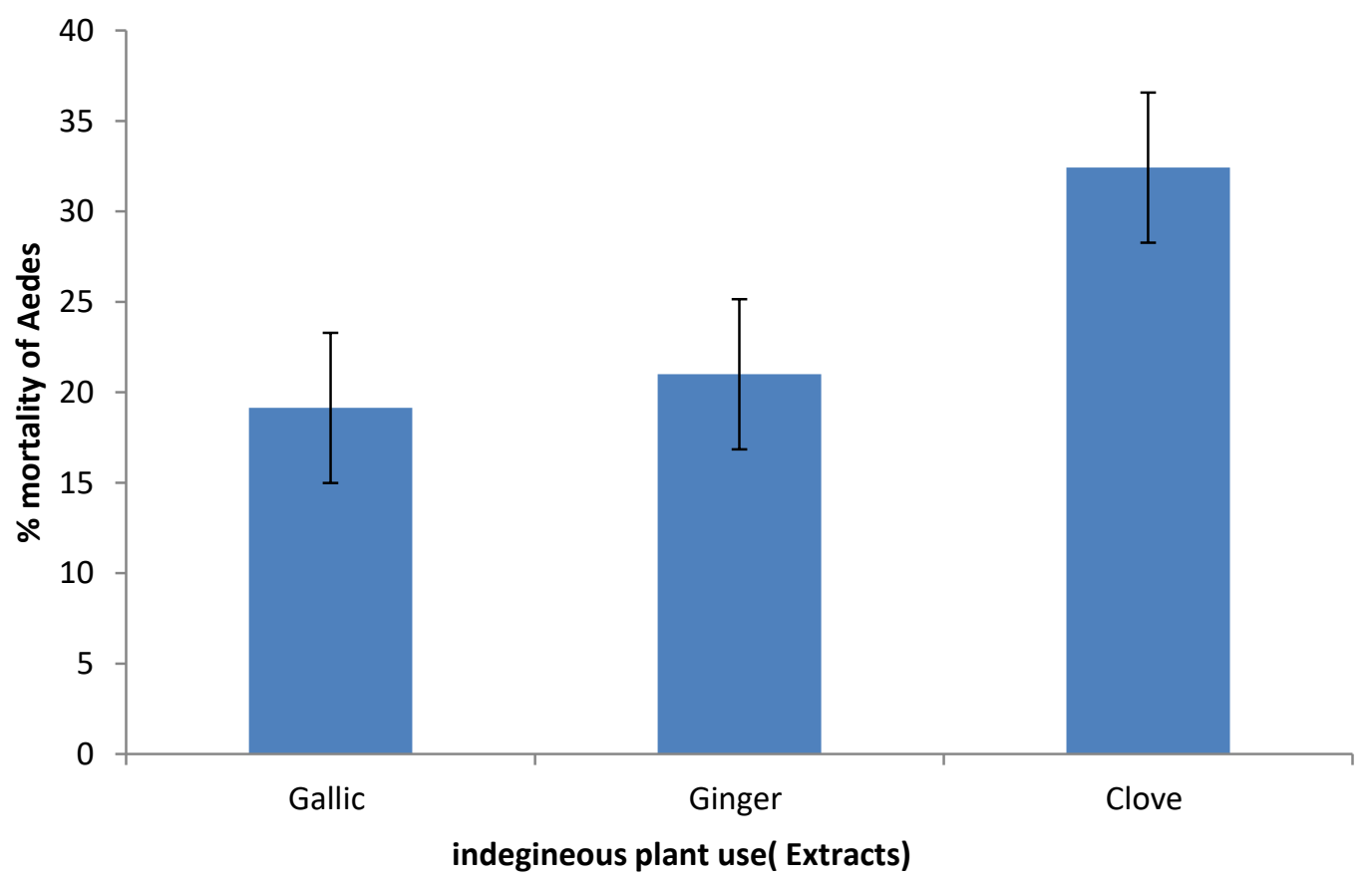

Fig. 1. Effects of plants extract on perncetage mortality of Aedes sp. 
Table 3: Effect of plant extracts on different growth stages of the mosquito Aedes sp.

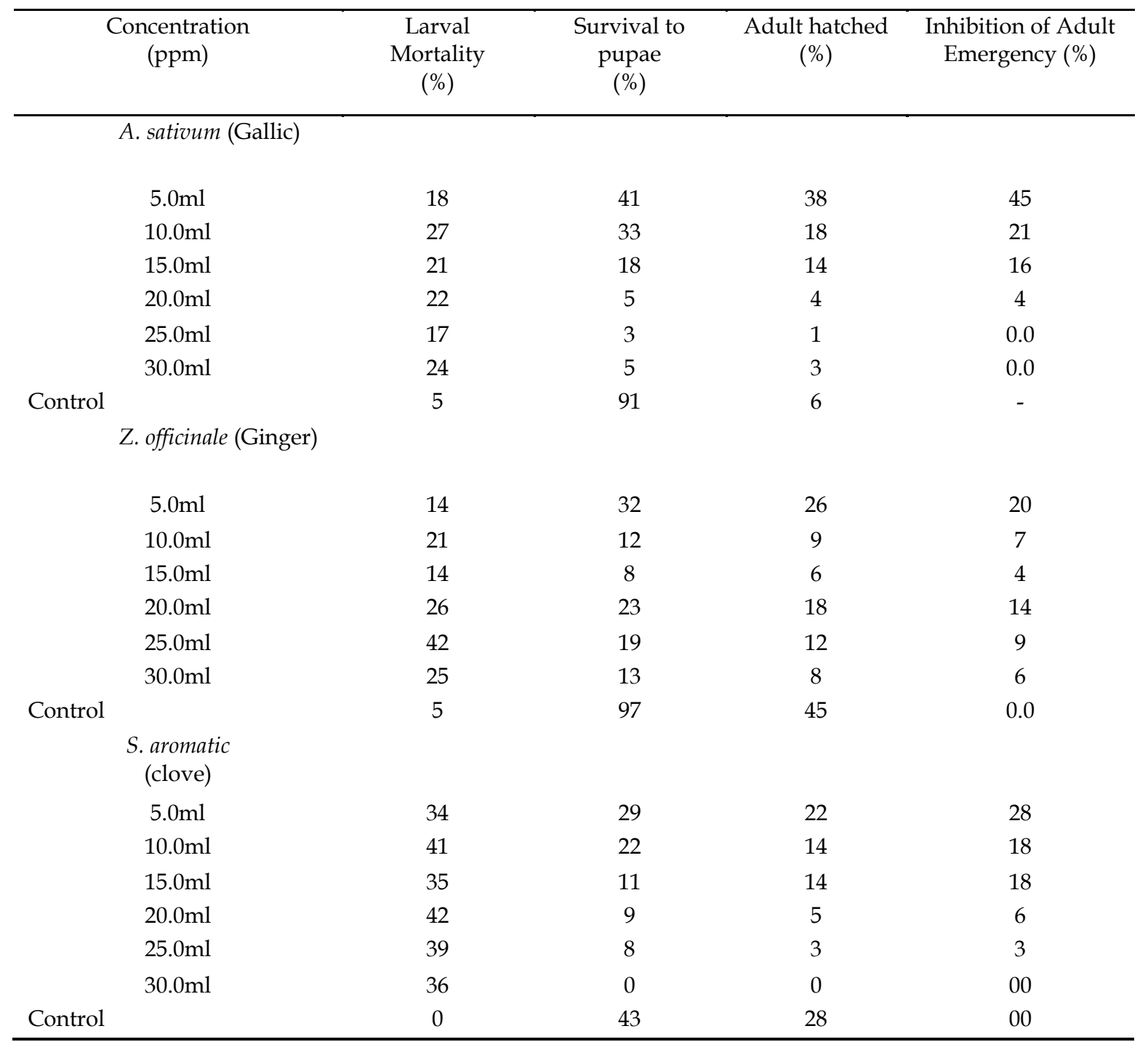

*Use d the equation Abbot (Abbott, 1993) to the percentage inhibition of treatments, according to those in control (Untreated). With six (6) replicates (larvae/replicate)

\section{Effect of plant extracts on different growth stages of Aedes mosquitoes.}

Results of laboratory testing for three plants extracts of $A$. sativum, Z. officinale and S. aromatic were screened for larvarcidal activities such as LC $_{50}$ (larvae mortality) and adult survival (\%). From the result (Table. 3) compare with control and treatment group A. sativum showed highest survival from pupa to adult $(41 \%, 38 \%$ and $45 \%)$ recorded, followed by S. aromatic with $(29 \%, 22 \%$ and $28 \%)$ and $Z$. officinale recorded the least activity among all the concentration $(32 \%, 26 \%$ and $20 \%$ ) respectively. With increasing concentration of $5.0 \mathrm{~m}$, $12.0 \mathrm{~m}, 20.0 \mathrm{~m}, 25.0 \mathrm{~m}$ and $30.0 \mathrm{~m}$ when compare to control group (Table. 3 )

\section{DISCUSSION}

Plant could be an alternative source for mosquitocidal because they constitute a potential source of bioactive compounds and are general free from harmful effects. In the present study experimental results of solvent extracts of three indigenous plants A. sativum, $Z$. officinale and $S$. aromatic were accessed and revealed to be toxic to immature stages of Aedes 
mosquitoes. From the experiment the earlier instars larvae are more susceptible than the late instars (Murugalet al. 2012).

Results of laboratory testing for three plants extracts of A. sativum, Z. officinale and S. aromatic were screened for larvarcidal activities such as $\mathrm{LC}_{50}$ (larvae mortality) and adult survival (\%). From the result (Table. 1) compare with control and treatment group A. sativum showed highest survival from pupa to adult $(41 \%, 38 \%$ and $45 \%)$ recorded, followed by S. aromatic with $(29 \%, 22 \%$ and $28 \%)$ and $Z$.officinale recorded the least activity among all the concentration $(32 \%, 26 \%$ and $20 \%)$ respectively. With increasing concentration of $5.0 \mathrm{~m}$, $12.0 \mathrm{~m}, 20.0 \mathrm{~m}, 25.0 \mathrm{~m}$ and $30.0 \mathrm{~m}$ compare to control group (Table. 1). These results are also comparable to the earlier report of Murugal et al. (2012) with Culex and Anopheles sp.

All plants extracts shows toxic effects on Aedes sp after 24h of exposed at different concentration (mg/l). However the highest mortality was found in A. sativum and Z. officinale against larvae of Aedes mosquitoes with $\mathrm{LC}_{50}=42.50 \%$ and $\mathrm{LC}_{50}=30.01 \%$ respectively (Table.2) while $S$. aromantic was found to have lowest mortality at $\mathrm{LC}_{50}=24.50 \%$. Similar report from prathibha et al. (2011) with $\mathrm{LC}_{50}$ value in $4^{\text {th }}$ instars larvae. $\mathrm{LC}_{50}=5.388, \mathrm{LC}_{50}=$ 6.288 , and 10.73 respectively.

Inhibition of growth was detected with the extract since all larvae grew to become pupae and subsequently emerged to adult (Table 3). Earlier report (Bangavan et al., 2008) reveals that extracts of $A$. aromatic, showed larvacidal activity against the earlier and fourth instars larvae of Aedes mosquitos'species, while Present study showed A. aromatic extract has effects on both first third and fourth instar larvae of Aedes mosquitoes. Furthermore, results of the present study may contribute to reduction of application of synthetic insecticides, which in turn increase the opportunity for natural control of medically important pest by botanical pesticides or insecticides (Govindarajan, 2008).

\section{CONCLUSION}

The results of laboratory testing for three indigenous plants A. sativum, Z. officinale and S. aromatic were screened for larvae to adult survival (\%) rates with effects of extracts. From the results $A$. sativum showed highest survival from pupa to adult recorded, followed by $\mathrm{S}$. aromatic the least activity among all the concentration $(5.0 \mathrm{~m}, 12.0 \mathrm{~m}, 20.0 \mathrm{~m}, 25.0 \mathrm{~m}$ and $30.0 \mathrm{~m})$ respectively. In the preliminary screening, potential larvacidal activity of different plant extracts A. sativum, Z. officinale and S. aromatic were noted with seven (7) replicates against Aedes sp and percentage mortality was observed and recorded among. However the highest mortality was found in A. sativum and Z. officinale against larvae of Aedes mosquitoes with $\mathrm{LC}_{50}=42.50$ and $\mathrm{LC}_{50}=30.01 \mathrm{mg} / 1$ respectively. While $S$. aromantic was found to have lowest mortality at $\mathrm{LC}_{50}=24.50$. Data obtained were analyzed by comparing experimental groups and control groups with significance level established at $\mathrm{p}<0.05$.

These researches recommended that A. sativum (Gallic), S. aromatic (Clove) has the shows more larvacidal activity against mosquito's species (Aedes, Culex and Anopheles) and could be served as alternative form of botanical control to insects and pest (insecticides and pesticides). Further studies on the tested plant should include mode of actions under field conditions. 


\section{REFERENCES}

Abbott, W.S. (1999); a method of computing the effectiveness of insecticides. America Journal of Entomology, 18: 265 - 267.

Ameen G.H., Rembold, H., Ahmed, A.A.I. and Breuer, A.M., (1983). Effect of Melia azedarach fruit extract on juvenile hormone titer and protein content in the hemolymph of two species of noctuid lepidopteran larvae (Insecta: Lepidoptera: Noctuidae). Phytoparasitica., 26: 283-291.

Arsenual, E.S., Morais, S.M., Lima, M.A. and Santana, E.W. (2008); Larvicidal activity of essentials oils from Brazilian plants against Aegypti. Mem. Inst. Oswaldo Cruz., 99(5): $541-544$.

Bagavan, A., Elango, G., Rahuman, A.A., Kamaraj, C.and Zahir, A.A. (2010); Studies on effects of indigenous plant extracts on filarial vector Culex tritaeniorhynchus Giles. Parasitology. Res.,107: 167- 176.

Bagavan, A., Rahuman, A.A., Kamaraj, C. and Geetha, K. (2008) Larvicidal activity of saponin from Achyranthesasperaagainst Aedesaegypti and Culexquinquefa sciatus(Diptera: Culicidae). Parasitology. Res.,103(1): 223-229.

Banerji, S.K., Dua, V.K. and Sharma, V.P., 1995. Field studies on the mosquito repellent action of neem oil. Southeast Asian J. Trop. Med. Public Health, 26: 180-182

Barnard, M.O. (1999) Effect of Sorghum bicolor and Nerium oleander extracts on the grey flesh fly Calatropis nisprocella (Diptera: Sarcophagidae). Journal of Egypt. Ger. Soc. Zoology., 28: 233 - 243.

Beneli S. A., Banjo AD., Lawal OA., and Jonathan K., 2009. The efficacy of some plant extracts on Aedes Mosquitoes larvae. Academic Journal of Entomology, 2(1): 31-35

Chauret, R.C., Harshan, V., Saxena, A., Sukumaran, P., Sharma, M.C. and Lakshamana, K.M. (1998) Larvicidal and chemosterillant activity of Annona squamosa alkaloids against An. stephensi. J. Am. Mosq. Control. Assoc., 9(1): 84 - 87.

De souza, E.E. and Bowen, M.F.(2011); Sensory physiological basis for attraction in mosquitoes. Journal of American Mosquito. Cont. Ass., 10: 316 - 325.

Des, A., Nassima, R. and Noureddine, S. (2009) Larvicidal Activity of a Neem Tree Extract (Azadirachta) against mosquito larvae in the Republic of Algeria. J. Bio. Sc., 2: 15 - 22.

deterrent and ovicidal activity of solvent extracts of 50 plants against armyworm Spodoptera litura, Fab. (Lepidoptera: Noctuidae). Malaysian J. Appl. Biol., 33(2): 73 - 81.

Downe, G.S.G. and Rao, P.J. (1989) Neem (Azadirachta indica A. Juss) extracts as larval repellents and ovipositional deterrents to Spodoptera litura (Fabr.). Ind. J. Ent., 51: 121124.

Edilot, G., Rahuman, A.A., Kamaraj, C., Zahir, A.A. and Bagavan, A. (2004) Studies on effects of indigenous plant extracts on filarial vector Culex149 tritaeniorhynchus Giles. Parasitology. Res.,107: 167 -176.

Edriss, A.E., Alabjar, Z.A. and Satti, A.A. (2012) Phytochemical screening of important secondary metabolites in some extracts of two Sudanese plants, Global Adv. Res. J., 27: $115-120$.

Evans, V.P., Nagpal, B.N. and Srivastava Aruna., (1981). Effectiveness of neem oil mats in repelling mosquitoes. Trans $R$ Soc Trop Med Hyg., 87: 627-628.

Gerickke A.L, Schmutterer, H. (1990) Properties and potential of natural pesticides from the neem tree, Ann. Review Entomology., 35: 165 - 271.

Govindarajan, M., Jebanesan, A., Pushpanathan, T. and Samidurai, K. (2008) Studies on effect of Acalypha indica L. (Euphorbiaceae) leaf extracts on the malarial vector, Anopheles stephensi Liston (Diptera: Culicidae). Parasitol. Res., 103 (3): 691 - 695.

Govindarajan, M., Mathivanan, T., Elumalai, K., Krishnappa, K. and Anandan, A. (2011) Ovicidal and repellent activities of botanical extracts against Culex quinquefasciatus, 
Aedes aegypti and Anopheles stephensi (Diptera: Culicidae). Asian. Pac. J. Trop. Biomed.,1(1): $43-48$.

Hafeez. M., Hanafi Bojd, A.A., Iranshahi. M., Vatandoost, H. and Hanafi Bojd, M.Y. (2010) Larvicidal efficacy of latex and extract of Calotropis procera (Gentianales: Asclepiadaceae) against Culex

Haque, E.A.S., Canyonb, D., Younesc, M.W.F., Abdel Wahaba, H., and Mansoura, A.H. (2009) A review of botanical phytochemicals with mosquitocidal potential. Environ Int., 3: 1149 - 1166.

James, N., Jayakumar, M., Elumalai, K., Jeyasankar, A., Muthu, C. and Ignacimuthu, S. (2004) Oviposition

Jeyabalalan, H. (2003) The Neem Tree Azadirachta indica (A. Jass) and Other Meliaceous Plants:Sources of Unique Natural Products for Integrated Pest Management, Medicine, Industry and other Purposes, VCH, Weinheim, Germany, pp. 696.

Lutomiah, Marina, Armando Ulloa, Arnoldo Orozco- Bonilla, Miguel Munoz and Trevor Williams, (2010); Diversity of mosquitoes and the aquatic insects associated with their oviposition sites along the Pacific coast of Mexico. Parasitology. Vectors, 7: 14 17.

Murugal, D., Arul, N. and Thangamathi, P. (2012); Studies on effects of Pelargonium citrosa leaf malarial vector Anopheles stephensi Liston (Diptera: Culicidae). Acta Tropica, 96: 47-55.Medical Research Bulletin, 33(1):10.

Murugan, K. and Jeyabalan, D. (1999) Mosquitocidal effect of certain plant extracts on Anopheles, Journal of indian entomology rev. 118

Ormany, M. and Mohan, D. R. (2008) Evaluation of the larvicidal activity of the leaf extract of a

Prathibal E.F., Emosairue SO., and Hassanali A.(2012); Bioactive of Xylopia aetiopica (Dunal) (Diptera: Culicidae) J. Vector. Borne, weed plant, Ageratina adenophora, against two important species of mosquitoes, Aedes aegypti and Culex quinquefasciatus. Afr. J. Biol., $8(6), 731-738$.

Schmutterer, H., 1990. Properties of natural pesticides from the neem tree, Azadirachta indica. Ann. Rev Entomol., 35:271-297.

Wreka. A., Haldar, K.M., Ghosh, A. and Chandra, G. (2007) Larvicidal activities of three plants against filarial vector Culex quinquefasciatus Say (Diptera: Culicidae). Parasitol. Res.,105 (5): 1411 - 1417. 